\title{
Interleukin-18 production and pulmonary function in COPD
}

\author{
H. Imaoka*, T. Hoshino*, S. Takei*, T. Kinoshita*, M. Okamoto*, T. Kawayama*, \\ S. Kato ${ }^{\#}$, H. Iwasaki ${ }^{\mp}$, K. Watanabe ${ }^{+}$and H. Aizawa*
}

ABSTRACT: Interleukin (IL)-18 production and pulmonary function were evaluated in patients with chronic obstructive pulmonary disease (COPD) in order to determine the role of IL-18 in COPD.

Immunohistochemical techniques were used to examine IL-18 production in the lungs of patients with very severe COPD (Global Initiative for Chronic Obstructive Lung Disease (GOLD) stage IV, $n=16)$, smokers $(n=27)$ and nonsmokers $(n=23)$. Serum cytokine levels and pulmonary function were analysed in patients with GOLD stage I-IV COPD $(n=62)$, smokers $(n=34)$ and nonsmokers $(n=47)$.

Persistent and severe small airway inflammation was observed in the lungs of ex-smokers with very severe COPD. IL-18 proteins were strongly expressed in alveolar macrophages, CD8+ Tcells, and both the bronchiolar and alveolar epithelia in the lungs of COPD patients. Serum levels of IL-18 in COPD patients and smokers were significantly higher than those in nonsmokers. Moreover, serum levels of IL-18 in patients with GOLD stage III and IV COPD were significantly higher than in smokers and nonsmokers. There was a significant negative correlation between serum IL-18 level and the predicted forced expiratory volume in one second in patients with COPD. In contrast, serum levels of IL-4, IL-13 and interferon- $\gamma$ were not significantly increased in any of the three groups.

In conclusion, overproduction of interleukin-18 in the lungs may be involved in the pathogenesis of chronic obstructive pulmonary disease.

KEYWORDS: Chronic obstructive pulmonary disease, chronic obstructive pulmonary disease clinical/basic investigations, cytokine production

hronic obstructive pulmonary disease (COPD) is an important pulmonary inflammatory disease of which the prevalence and associated mortality rates have been predicted to rise. Smoking is recognised as the largest risk factor for COPD, and quitting smoking is thought to be important in the prevention and control of COPD $[1,2]$. However, there is, as yet, no effective treatment for pulmonary inflammation in COPD.

Increased numbers of CD8+ T-cells, alveolar macrophages and neutrophils are characteristic pathological features of the lungs in COPD [3, 4]. Eosinophil numbers are increased during exacerbations and possibly also during stable phases in a subset of patients [5]. These activated inflammatory cells can release various mediators, including leukotriene $\mathrm{B}_{4}$ and inflammatory cytokines (e.g. Thelper cell (Th) types 1 and 2 cytokines, and tumour necrosis factor (TNF)- $\alpha$ ) [6]. The Th1 cytokine interferon (IFN)- $\gamma$ may contribute to the onset of COPD [7]. For example, previous studies have demonstrated positive correlations between CD8+ cell numbers and the degree of COPD airflow limitation [8]. The CD8+ lymphocytes are believed to be predominantly cytotoxic T-cells type 1 that produce IFN- $\gamma$ [7]. One study [9] reported that the level of IFN- $\gamma$-inducible protein-10 (CXC chemokine ligand 10) was also increased in the lungs of COPD patients, but recent studies $[10,11]$ have reported that IFN- $\gamma$ production in the lungs of these patients is not significantly greater than in healthy controls. In mice models, pulmonary emphysema has been induced by doxycycline in lung-specific IFN- $\gamma$ transgenic (Tg) mice [12]. The Th2 cytokines interleukin(IL)-4 and -13 are also thought to be involved in the pathogenesis of COPD. For instance, levels of IL-4 and -13 are significantly greater in the central airways of

\section{AFFILIATIONS}

${ }^{*}$ Division of Respirology, Neurology and Rheumatology, Dept of Medicine, Kurume University School of Medicine, Kurume,

"Dept of Pathology and ${ }^{+}$4th Dept of Internal Medicine, Fukuoka University School of Medicine, Fukuoka, and "Division of Pathology and Cell Biology, Graduate School and Faculty of Medicine, University of the Ryukyus, Okinawa, Japan.

\section{CORRESPONDENCE}

T. Hoshino

Division of Respirology

Neurology and Rheumatology

Kurume University School of

Medicine

Kurume

Fukuoka 830-0011

Japan

Fax: 81942317560

E-mail: hosino@med.kurume-u.ac.jp

Received:

February 162007

Accepted after revision:

October 242007

\section{SUPPORT STATEMENT}

This work was supported by: a Grantin-Aid for Scientific Research (B); (no. 17390244) and a Grant-in-Aid for Exploratory Research (no. 18659244) from the Ministry of Education, Science, Sports and Culture of Japan; a grant from the Kakihara Foundation (Fukuoka, Japan); a grant from the Takeda Science Foundation (Osaka, Japan) to T. Hoshino; and a Grant-in-Aid for Scientific Research (B): (no. 18390244) to H. Aizawa.

STATEMENT OF INTEREST None declared. 
smokers with chronic bronchitis than in those of asymptomatic smokers [10]. In contrast, a previous study [11] reported decreased expression of IL-13 in the lungs of COPD patients. Overproduction of IL-13 induced in the lungs of adult mice by a doxycycline-dependent Clara cell secretory protein promoter induces emphysema [13].

IL-18 is a proinflammatory cytokine produced intracellularly from a biologically inactivated precursor, pro-IL-18. Mature IL18 is secreted after cleavage of pro-IL-18 by caspase-1, originally identified as IL- $1 \beta$ converting enzyme. Activated macrophages produce large amounts of mature IL-18 after cleavage of pro-IL-18 by caspase-1 [14]. It has been reported that low levels of pro- and mature IL-18 proteins are expressed in the lungs of healthy subjects [15]. HosHINO and co-workers [16-18] have shown that IL-18 can act as a co-factor for both Th1 and Th2 cell development, and several studies have subsequently reported that IL-18 may be involved in the development of Th2-type-diseases, such as asthma [14]. The present authors have previously demonstrated that treatment with recombinant IL-18 plus IL-2 induces pulmonary inflammation and lung injury in mice [19], and IL-18 and its receptor are strongly expressed in the human lung in idiopathic pulmonary fibrosis [15]. Very recently, the present authors reported that constitutive IL-18 overproduction in the lungs of mice induces emphysema [20]. Taking these results together, it is anticipated that IL-18 is involved in the pathogenesis of pulmonary inflammatory diseases, such as lung fibrosis, lung injury and COPD.

The aim of the present study was to analyse the expression of IL-18 in the lungs and sera of COPD patients in order to evaluate the role of IL-18 production in the pulmonary function of patients with COPD. Some of the results of the present study have been previously reported in the form of an abstract [21].

\section{MATERIALS AND METHODS}

\section{Subjects}

In total, 78 COPD patients (67 males and 11 females) were monitored at Kurume University Hospital (Kurume, Japan), Fukuoka University Hospital (Fukuoka, Japan), Chikugogawa Onsen Hospital (Ukiha, Japan), Kirigaoka Tsuda Hospital (Kitakyushu, Japan), Shigemoto Hospital (Shimonoseki,
Japan), Keisinkai Hospital (Tosu, Japan), Tokunaga-Naika Clinic (Fukuoka, Japan), the Social Insurance Futase Hospital (Iizuka, Japan) and Arao Central Hospital (Arao, Japan). All patients with COPD were diagnosed on the basis of clinical history, physical examination, chest radiograph, chest computed tomography and pulmonary function tests in accordance with the Global Initiative for Chronic Obstructive Lung Disease (GOLD) clinical criteria for the diagnosis and severity of COPD [22]. Exclusion criteria were: chronic lung conditions, such as asthma, bronchiectasis and interstitial lung diseases; cardiac, hepatic and renal failure; and current oral steroid therapy. Lung tissues were obtained from 16 patients with very severe COPD (GOLD stage IV) who had undergone lung volume reduction surgery (LVRS) at Fukuoka University Hospital. Control lung tissues were obtained from the normal tissues around preserved cancer specimens obtained after surgery from 23 nonsmokers and 27 smokers who underwent lung cancer extirpation at Kurume University Hospital. No patient was able to be sampled for both lung tissues and serum. Lung diseases (e.g. sarcoidosis, infectious diseases) were carefully excluded in control subjects, and ex-smokers were carefully excluded from the group of nonsmokers. Informed written consent was obtained from each subject and sample collection and all procedures were approved by the ethics committees of Kurume University and Fukuoka University.

\section{Pulmonary function tests}

Predicted normal Japanese values were used to calculate the forced expiratory volume in one second, (FEV1) \% predicted, which met the Japanese Pulmonary Function Standard in the Japanese Respiratory Society Statement [23]. Further details of these analyses are provided in the online supplementary data.

\section{Histology}

Samples of lung tissue were fixed with $10 \%$ formalin and embedded in paraffin wax. Between one and three paraffinembedded lung tissue samples were obtained from each subject. Sequential sections were made from each paraffinembedded lung tissue. Sections ( $4 \mu \mathrm{m}$ thick) were cut and placed on poly-L-lysine coated slides and then incubated overnight at $55-60^{\circ} \mathrm{C}$. Deparaffinised sections were stained with haematoxylin and eosin (HE).
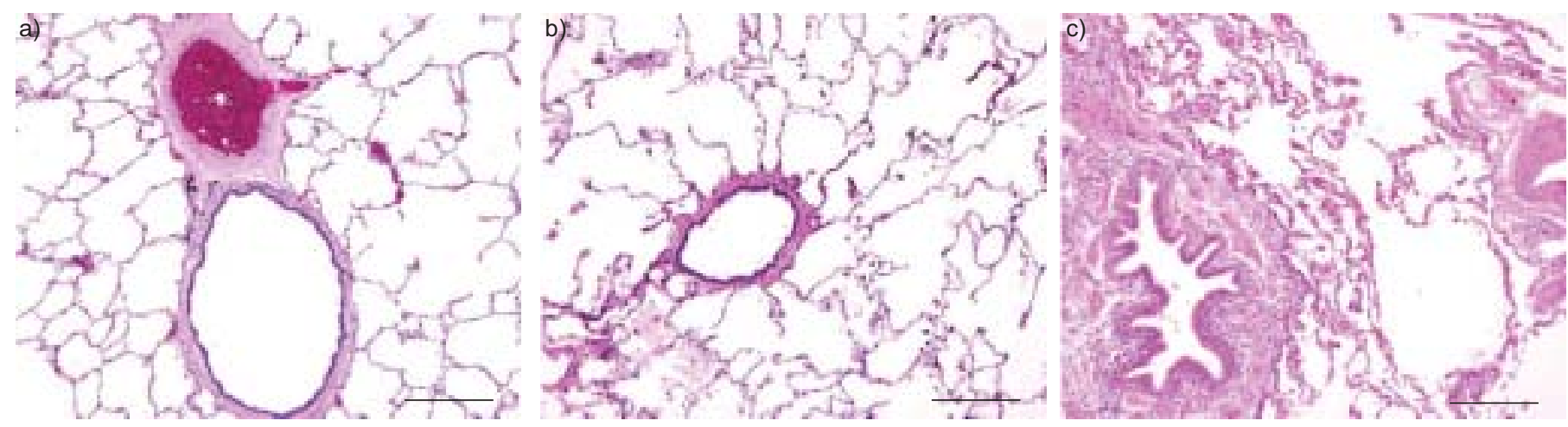

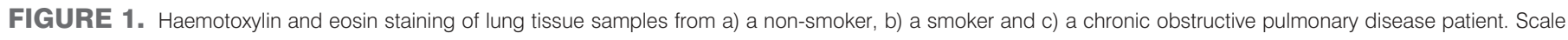
bars $=500 \mu \mathrm{m}$. 

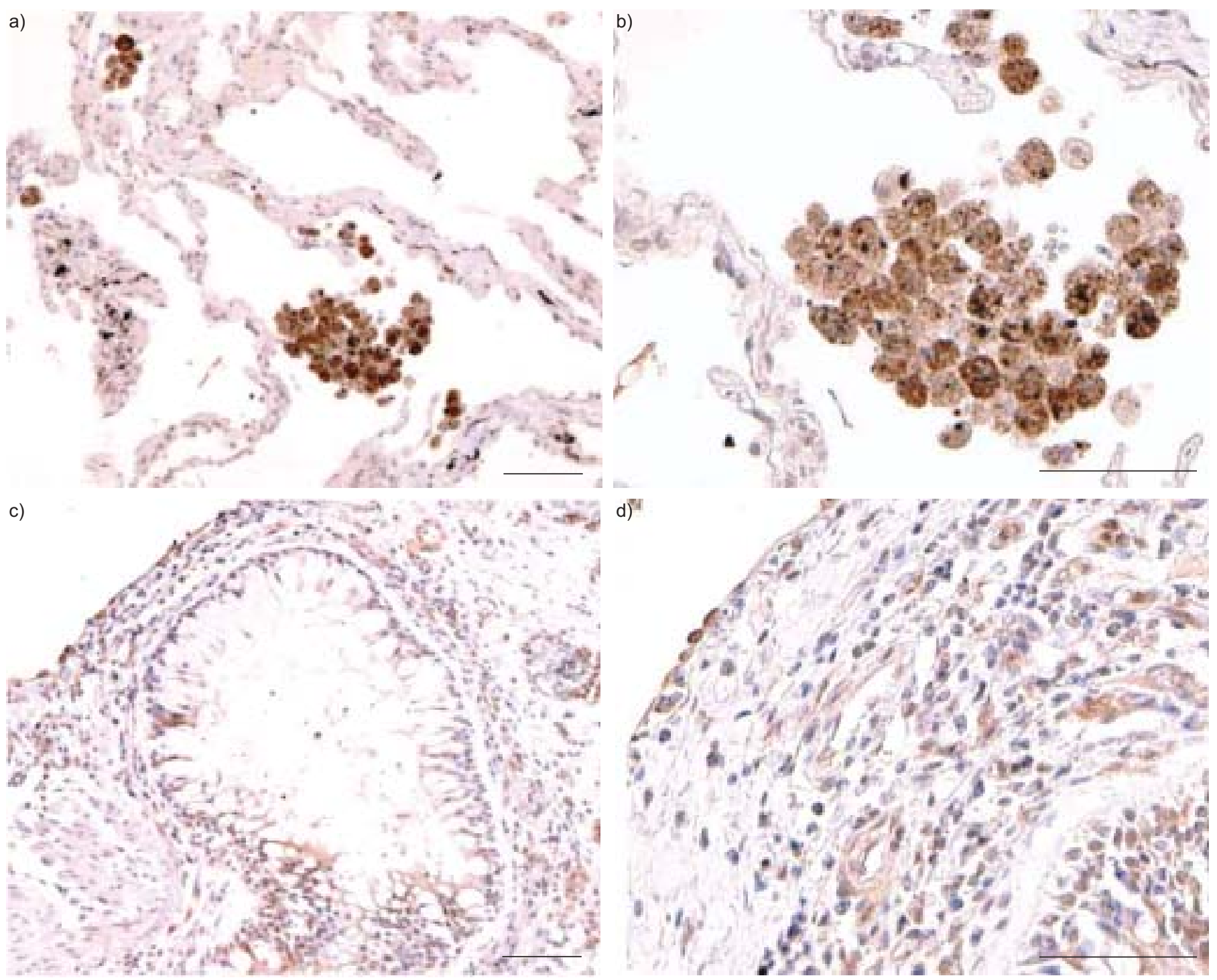

FIGURE 2. Immunostaining of lung tissue samples with mouse anti-interleukin-18 monoclonal antibodies in two patients (a and b) patient 1; (c and d) patient 2; with Global Initiative for Chronic Obstructive Lung Disease stage IV chronic obstructive pulmonary disease. Scale bars=100 $\mu \mathrm{m}(\mathrm{a}$ and $\mathrm{c})$ and $50 \mu \mathrm{m}(\mathrm{b}$ and d).

\section{Morphometric analysis}

The cross-sectional area occupied by the wall was quantified as a ratio of the total cross-sectional area, and the cross-sectional area occupied by the luminal mucosa was quantified as a ratio of the total cross-sectional area by using a computer image analysis system as reported by HoGG et al. [24]. Digitised video images of the entire lung fields were analysed with a computerised colour image analysis software system (Win Roof Version 5.0; Mitani Co., Fukui, Japan) as recently reported elsewhere [20]. Further details of these analyses are provided in the online supplementary data.

\section{Immunohistochemical assay}

Immunohistochemical analysis was performed as reported previously [15]. Anti-human IL-18 (clone 8 (mouse immunoglobulin (Ig)G2a) and clone 1-8D (mouse IgG1)) monoclonal antibodies (mAbs) were used. IL-18 positive reactivity was identified by biotin-labelled goat anti-mouse and rabbit $\mathrm{Ig}$, peroxidase-streptavidin and 3-3'-diaminobenzidine-4HCl (Dako, Kyoto, Japan). Double immunohistochemical analysis for IL-18 production in CD4-, CD8-, or CD13-positive cells was also performed. Anti-human CD4 (4B12 (mouse IgG2a); Novocastra, Newcastle upon Tyne, UK), anti-human CD8 (C8/144B (mouse IgG1); Dako) and anti-human CD13 (38C12 (mouse IgG1); Novocastra) mAbs were used. CD4, CD8 and CD13 positive reactivity was identified by the addition of biotin-labelled porcine anti-mouse, anti-rabbit and anti-goat Ig, alkaline phosphatasestreptavidin and Fast Red (Dako). Further details of these analyses are provided in the online supplementary data.

Quantitative assessment of alveolar macrophages and infiltrating mononuclear cells in the general interstitium of lung tissue

Quantitative assessment of alveolar macrophages and infiltration of mononuclear cells was performed as reported previously [15]. Briefly, HE sections of lung tissues obtained from COPD patients who had undergone LVRS were viewed and, in 


\begin{tabular}{|c|c|c|c|c|c|c|}
\hline & \multirow[t]{2}{*}{ Subjects n } & \multirow[t]{2}{*}{ Age yrs } & \multicolumn{2}{|c|}{ Total cells $\cdot \mathrm{mm}^{-2}$} & \multicolumn{2}{|c|}{ Immunoreactivity IL-18 positive cells $\cdot \mathrm{mm}^{-2}(\%)$} \\
\hline & & & AMs & IMNCs & AMs & IMNCs \\
\hline Nonsmoker & 23 & & & & & \\
\hline Smoker & 27 & & & & & \\
\hline Male & 16 & $67.9 \pm 2.0$ & $16.5 \pm 2.8^{\star}$ & $12.8 \pm 2.7^{\star}$ & $7.1 \pm 1.3(42.0 \pm 1.3)$ & $4.2 \pm 0.8(35.0 \pm 1.7)^{*}$ \\
\hline Female & 11 & $60.5 \pm 3.1$ & $17.0 \pm 1.4^{*}$ & $13.9 \pm 0.7^{\star}$ & $6.3 \pm 0.6(37.1 \pm 1.8)$ & $3.9 \pm 0.3(28.0 \pm 2.2)^{*}$ \\
\hline \multicolumn{7}{|l|}{ Patient $^{\#}$} \\
\hline 1 & 1 & 71 & 35.1 & 79.3 & $27.0(77.2)$ & $43.6(55.0)$ \\
\hline 6 & 1 & 72 & 62.3 & 91.7 & $45.5(73.1)$ & $48.9(53.4)$ \\
\hline 7 & 1 & 65 & 78.9 & 114.1 & $62.2(78.9)$ & $65.6(57.5)$ \\
\hline 8 & 1 & 72 & 68.2 & 86.0 & $56.8(83.4)$ & $46.0(53.6)$ \\
\hline 9 & 1 & 53 & 74.7 & 88.1 & $68.4(91.6)$ & $44.2(50.2)$ \\
\hline 10 & 1 & 56 & 66.0 & 69.3 & $52.5(79.6)$ & $32.5(47.0)$ \\
\hline 11 & 1 & 78 & 54.3 & 95.0 & $45.5(83.9)$ & $44.1(46.5)$ \\
\hline 12 & 1 & 71 & 61.2 & 68.0 & $52.8(86.3)$ & $29.5(43.5)$ \\
\hline 13 & 1 & 67 & 29.8 & 44.6 & $25.8(86.9)$ & $22.3(50.1)$ \\
\hline 14 & 1 & 73 & 106.8 & 102.4 & $90.0(84.3)$ & $50.3(49.2)$ \\
\hline 15 & 1 & 62 & 71.8 & 79.6 & $61.3(85.5)$ & $36.8(46.3)$ \\
\hline 16 & 1 & 72 & 37.0 & 100.0 & $35.5(96.2)$ & $50.0(50.0)$ \\
\hline
\end{tabular}

each HE section, three square fields $\left(2.5 \times 3.5 \mathrm{~mm}^{2} ; 8.75 \mathrm{~mm}^{2}\right)$, in which the small airway inflammation appeared most severe, were selected at $40 \times$ (fig. 1c). Within each of these square fields, a further three individual square fields $\left(1 \times 1.4 \mathrm{~mm}^{2}\right.$; $1.4 \mathrm{~mm}^{2}$ ) were selected at $100 \times$ (figs $2 \mathrm{a}$ and c). These smaller square fields were defined as the observation fields (OFs). Nine different OFs $\left(9 \times 1.4 \mathrm{~mm}^{2}\right)$ were selected within three different square fields $\left(3 \times 8.75 \mathrm{~mm}^{2}\right)$. The numbers of alveolar macrophages (AMs) and infiltrating mononuclear cells (IMNCs) in the general interstitium were counted within the nine OFs at $100 \times$ (figs $2 \mathrm{a}$ and c). For example, when $70 \mathrm{AMs}$ were counted within one OF at $100 \times$, the number of AMs was 50 cells $\cdot \mathrm{mm}^{-2}$. The total number of AMs and IMNCs in nonsmokers, smokers and COPD patients was expressed as mean $\pm \mathrm{SEM}$ cells $\cdot \mathrm{mm}^{-2}$ (table 1 ). Two pathologists examined these sections independently and in a blinded manner, without prior knowledge of the patients' clinical status.

\section{Quantitative assessment of cells producing IL-18}

Percentages of IL-18 positive cells in AMs, IMNCs, CD4+, $\mathrm{CD} 8+$, and CD13+ cells were previously assessed as previously reported [15]. Nine different OFs $\left(9 \times 1.4 \mathrm{~mm}^{2}\right)$ were selected at $100 \times$ within three different square fields $\left(3 \times 8.75 \mathrm{~mm}^{2}\right)$, as described previously. The OFs were scanned under a microscope at $400 \times$ (figs $2 \mathrm{~b}$ and $\mathrm{d}$ ). The percentage of cells that expressed IL-18 were counted within three different areas on each OF at $400 \times$. Then, the mean percentage of cells that expressed IL-18 within nine OFs was calculated. The mean number of IL-18 positive cells $\cdot \mathrm{mm}^{-2}$ in AMs and IMNCs (table 1) was therefore calculated as:

(total no. of cells $\left.\cdot \mathrm{mm}^{-2}\right) \times($ mean percentage of cells expressing IL-18)

Two pathologists examined these sections independently, without prior knowledge of the patients' clinical status and in a blinded manner.

\section{Serum levels of IL-18, IL-13, IL-4, and IFN- $\gamma$}

Serum IL-18, -13, -4 and IFN- $\gamma$ levels were measured with commercially available ELISA kits (supplied by Medical and Biological Laboratories Co. Nagoya, Japan for IL-18 and R\&D Systems, Minneapolis, MN, USA for IL-13, IL-4, IFN- $\gamma$ ).

\section{Statistical analysis}

Results were expressed as means \pm SEM. Nonparametric tests (Kruskal-Wallis and Mann-Whitney U-tests) were used to compare differences between the groups. Correlations were 
TABLE 2 Clinical characteristics of chronic obstructive pulmonary disease (COPD) patients, smokers and nonsmokers examined by immunohistochemical analysis

\begin{tabular}{|c|c|c|c|}
\hline & Nonsmoker & Smoker & COPD \\
\hline Patients & 23 & 27 & 16 \\
\hline \multicolumn{4}{|l|}{ Sex } \\
\hline Male & 10 & 16 & 16 \\
\hline Female & 13 & 11 & 0 \\
\hline$\|$ & 0 & 0 & 0 \\
\hline III & 0 & 0 & 0 \\
\hline IV & 0 & 0 & 16 \\
\hline \multicolumn{4}{|l|}{ Smoking history } \\
\hline Current & 0 & 27 & 0 \\
\hline Ex-smoker $n$ (mean \pm SEM yrs since smoking cessation) & 0 & 0 & $16(9.5 \pm 1.8)$ \\
\hline FEV $1 \%$ pred & $107.8 \pm 3.9$ & $101.9 \pm 3.1$ & $24.5 \pm 1.4^{*,+}$ \\
\hline FEV1/FVC \% & $76.5 \pm 1.3$ & $73.6 \pm 1.1$ & $26.9 \pm 1.3^{*,+}$ \\
\hline \multicolumn{4}{|l|}{ Treatment } \\
\hline Systemic steroids & 0 & 0 & 0 \\
\hline Inhaled corticosteroids & 0 & 0 & $6(37.5)^{\#}$ \\
\hline Bronchodilators & 0 & 0 & $16(100)$ \\
\hline No drug treatment & $23(100)$ & $27(100)$ & 0 \\
\hline
\end{tabular}

Data are presented as $n, n(\%)$ or mean \pm SEM, unless otherwise stated. GOLD: Global Initiative for Obstructive Lung Disease; BMI: body mass index; VC: vital capacity; FVC: forced VC; \% pred: \% predicted; FEV 1 : forced expiratory volume in one second. ${ }^{*}$ : three COPD patients were receiving inhaled beclomethasone dipropionate $400 \mu \mathrm{g} \cdot$ day $^{-1}$ and three were receiving $800 \mu \mathrm{g} \cdot$ day $^{-1}$. All six were also receiving bronchodilators. ${ }^{\because}: \beta_{2}$-agonists, anticholinergics and/or methylxanthines. *: $p<0.05$ versus nonsmokers; ${ }^{+}: p<0.05$ versus smokers.

analysed by simple regression. A $\mathrm{p}<0.05$ was considered to be statistically significant.

\section{RESULTS}

\section{Clinical findings}

Tables 2 and 3 provide details (number, age, sex, GOLD stage, smoking history, body mass index, pulmonary function and treatment) of all individuals subjected to the immunohistochemical and ELISA analyses. All of the 16 COPD patients who had undergone LVRS had stopped smoking 2-21 yrs previously (mean $9.5 \pm 1.8 \mathrm{yrs}$ ). Three COPD patients who had undergone LVRS had received inhaled beclomethasone dipropionate $400 \mu \mathrm{g} \cdot \mathrm{day}^{-1}$ and three were receiving $800 \mu \mathrm{g} \cdot \mathrm{day}^{-1}$. All 16 patients were receiving bronchodilators, such as $\beta_{2^{-}}$ agonists, anticholinergics and/or methylxanthines. Sera were obtained from 62 COPD patients, 47 nonsmokers and 34 current smokers for ELISA analysis. In total, 30 of these COPD patients had stopped smoking 2-21 yrs previously (mean $7.6 \pm 1.0$ yrs). Four patients with severe COPD (GOLD stage III) were receiving inhaled fluticasone $400 \mu \mathrm{g} \cdot \mathrm{day}^{-1}$, and one was receiving $800 \mu \mathrm{g} \cdot \mathrm{day}^{-1}$. Five patients with very severe COPD (GOLD stage IV) were receiving fluticasone $400 \mu \mathrm{g} \cdot \mathrm{day}^{-1}$ and five were receiving $800 \mu \mathrm{g} \cdot \mathrm{day}^{-1}$. All of the $15 \mathrm{COPD}$ patients receiving fluticasone also received bronchodilators, such as $\beta_{2^{-}}$ agonists, anticholinergics and/or methylxanthines. All the
COPD patients analysed were clinically stable and experienced no disease exacerbations during the previous 3 months.

\section{Persistent and severe airway inflammation in COPD patients}

Severe small airway remodelling, such as increase in the thickness of the wall, hyperplasia of the mucosa and presence of mucous exudates in the lumen, was observed in the lungs of COPD patients (fig. 1c). The computer image analysis system previously reported [24] was used to quantify both the wall area and the luminal mucosa area as ratios of the total airway area in six COPD stage IV patients who had undergone LVRS, six smokers, and six nonsmokers. The wall to total area ratios were $34.7 \pm 2.5 \%$ (COPD patients), $8.8 \pm 0.9 \%$ (smokers), and $10.3 \pm 1.1 \%$ (nonsmokers); and the respective luminal mucosa to total area ratios were $18.7 \pm 1.5 \%, 11.2 \pm 0.9 \%$, and $9.5 \pm 1.2 \%$, respectively. Both ratios in COPD patients were significantly $(\mathrm{p}<0.01)$ higher than those in smokers and nonsmokers. Computer image analysis clearly revealed severe airway remodelling in the COPD patients, as reported by a previous study [24]. Quantitative analysis revealed that the numbers of AMs and IMNCs in the lungs of patients with very severe COPD who had stopped smoking $>2$ yrs previously were significantly $(\mathrm{p}<0.05)$ greater than in nonsmokers and smokers. The numbers of AMs and IMNCs were also significantly 


\begin{tabular}{|c|c|c|c|c|}
\hline \multirow[t]{2}{*}{ TABLE 3} & \multicolumn{4}{|c|}{$\begin{array}{l}\text { Clinical characteristics of chronic obstructive pulmonary disease (COPD) patients, smokers and nonsmokers examined } \\
\text { by ELISA analysis }\end{array}$} \\
\hline & & Nonsmoker & Smoker & COPD \\
\hline Patients & & 47 & 34 & 62 \\
\hline Age yrs & & $61.4 \pm 2.7$ & $60.7 \pm 2.4$ & $67.5 \pm 1.0$ \\
\hline \multicolumn{5}{|l|}{ Sex } \\
\hline Female & & 27 & 8 & 11 \\
\hline \multicolumn{5}{|l|}{ GOLD stage } \\
\hline 1 & & 0 & 0 & 14 \\
\hline$\|$ & & 0 & 0 & 19 \\
\hline III & & 0 & 0 & 16 \\
\hline IV & & 0 & 0 & 13 \\
\hline $\mathrm{BMI} \mathbf{k g} \cdot \mathrm{m}^{-2}$ & & $21.6 \pm 0.8$ & $20.5 \pm 0.7$ & $21.1 \pm 0.3$ \\
\hline vc \% pred & & $106.4 \pm 3.7$ & $106.0 \pm 3.4$ & $88.5 \pm 3.4^{\star \bullet}$ \\
\hline FEV $1 \%$ prec & & $109.0 \pm 4.1$ & $104.0 \pm 3.3$ & $55.3 \pm 3.2^{* .9}$ \\
\hline $\mathrm{FEV}_{1} / \mathrm{FVC} \%$ & & $83.7 \pm 1.4$ & $78.5 \pm 1.2$ & $46.9 \pm 1.7^{\star}$ \\
\hline \multicolumn{5}{|l|}{ Treatment } \\
\hline Systemic s & roids & 0 & 0 & 0 \\
\hline Inhaled cor & costeroids & 0 & 0 & $15(24.2)^{+}$ \\
\hline Bronchodil & ors $^{f}$ & 0 & 0 & 33 (53.2) \\
\hline No drug tre & tment & $47(100)$ & $34(100)$ & $29(46.8)$ \\
\hline
\end{tabular}

Data are presented as $n, n(\%)$ or mean \pm SEM, unless otherwise stated. GOLD: Global initiative for Obstructive Lung Disease; BMI: body mass index; VC: vital capacity; FVC: forced VC; \% pred: \% predicted; FEV1: forced expiratory volume in one second. *: smoking history in patients with stage I, II, III, and IV COPD were 53.4 \pm 8.3 , $60.0 \pm 7.1,53.3 \pm 5.8$ and $50.0 \pm 4.0$ pack-yrs, respectively. ${ }^{+}$: all were receiving inhaled corticosteroids (fluticasone $400-800 \mu \mathrm{gg} \cdot$ day $^{-1}$ ) plus bronchodilators. ${ }^{f}: \beta_{2^{-}}$ agonists, anticholinergics and/or methylxanthines. *: $p<0.05$ versus nonsmokers; ${ }^{\circ}: p<0.05$ versus smokers.

$(\mathrm{p}<0.05)$ greater in the lungs of smokers than of nonsmokers. There were no significant differences in the numbers of AMs and IMNCs in the lungs of male and female smokers (16 versus 11 , respectively) or in the lungs of male and female nonsmokers (10 versus 13 , respectively; table 1 ).

\section{Increased expression levels of IL-18 in the lungs of COPD patients}

The airway epithelial cells in the lungs of nonsmokers weakly expressed IL-18 protein, as previously reported [15]. Approximately $30-50 \%$ of AMs in the lungs of nonsmokers and smokers weakly or modestly expressed IL-18 protein (table 1). In contrast, IL-18 protein was strongly expressed in $\sim 80 \%$ of AMs and in some IMNCs in the lungs of COPD patients (fig. 2). In addition, IL-18 was strongly expressed in both the bronchiolar and alveolar epithelium in patients with very severe COPD (GOLD stage IV; fig. 3). Microscopic tissue examination showed that type-2 pneumocytes expressed mainly IL-18 proteins. Quantitative analysis showed that IL18 expression levels were significantly $(\mathrm{p}<0.05)$ greater in AMs and IMNCs in the lungs of COPD patients than in those of nonsmokers and smokers. There were no significant differences between males and females in terms of IL-18 expression levels in AMs and IMNCs in the lungs of nonsmokers or smokers (table 1). Excess recombinant human IL-18 $\left(10 \mu \mathrm{g} \cdot \mathrm{mL}^{-1}\right)$ completely blocked all positive reactivity with anti-human-IL-18 antibodies (data not shown). These results indicated that anti-human-IL-18 mAbs specifically recognised IL-18 expression in the lungs of COPD patients.

\section{Numbers of IL-18-producing CD8+ T-cells were increased in the lungs of COPD patients}

Double immunostaining was performed with two different antibodies on one lung tissue slide in order to identify whether CD8+, CD4+, or CD13+ T-cells (presumably monocytes, eosinophils or macrophages) among the IMNCs produced IL18 proteins in 16 patients with very severe COPD. CD8, CD4 and CD13 positive cells were identified by Fast Red using fluorescence microscopy. Approximately $50-80 \%, 10-20 \%$ and $<10 \%$ of the IMNCs in the lungs of the 16 patients were CD8+, CD4+, and CD13+ cells, respectively (fig. 4, and data not shown). Of these, 91.5, 87.1 and $94.6 \%$, respectively, produced IL-18. The percentages of IL-18-positive CD8+, CD4+, and CD13+ cells did not differ significantly from each other (fig. 5). IL-18-producing CD $8^{+}$T-cells were barely observed in the lungs of nonsmokers and smokers (data not shown). These results showed that the proportions of IL-18-producing CD8+ T-cells were increased in the lungs of patients with very severe COPD. 

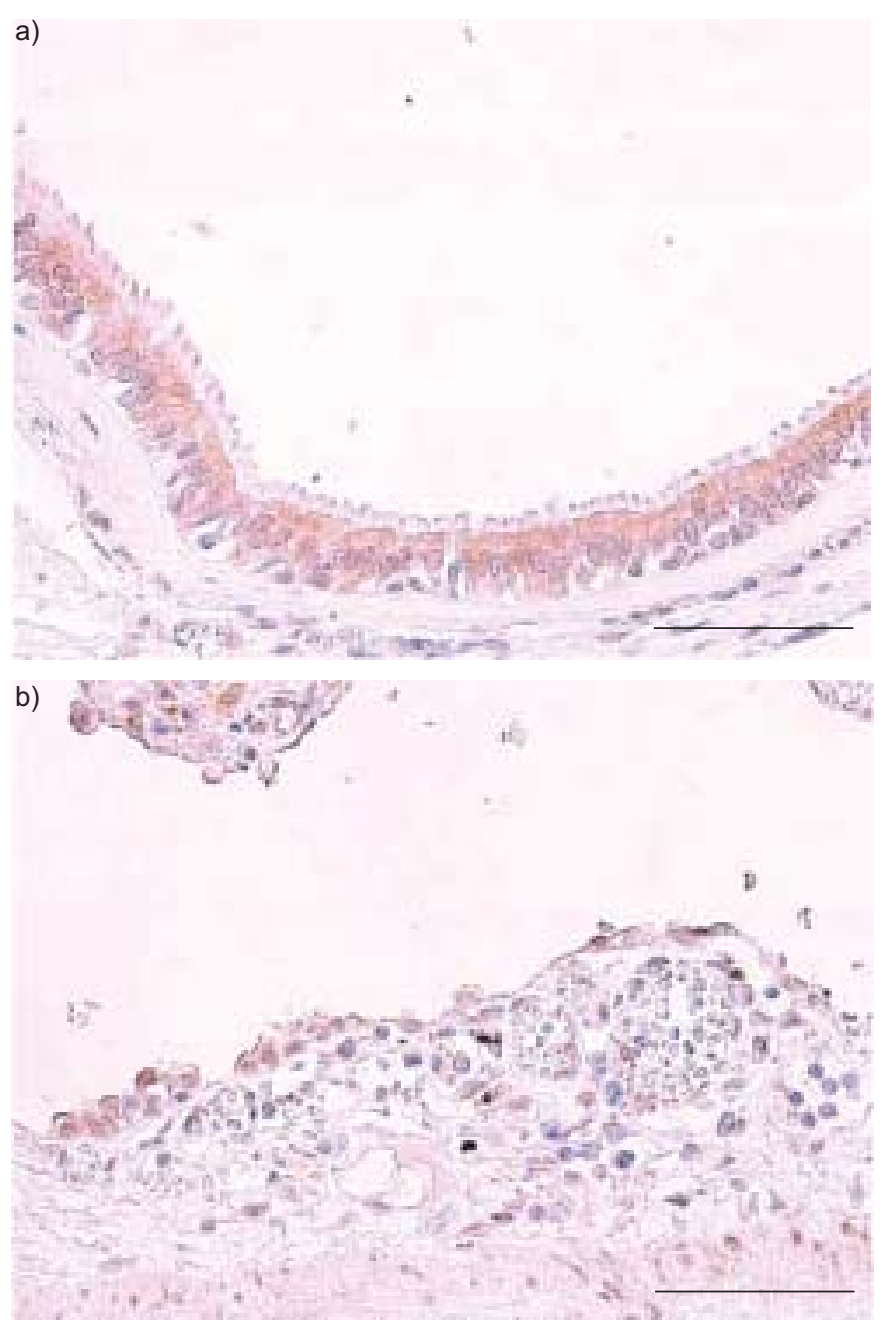

FIGURE 3. Immunostaining of lung tissue samples with mouse anti-interleukin18 monoclonal antibodies in chronic obstructive pulmonary disease patient 2 . Scale bars $=50 \mu \mathrm{m}$

\section{Increase in serum levels of IL-18 but not IL-13, -4, or IFN- $\gamma$ in} COPD patients

The immunohistochemical analysis suggested that IL-18 proteins produced in the lungs were circulating in the sera of COPD patients. Therefore, serum levels of IL-18, $-13,-4$, and IFN- $\gamma$ were analysed in COPD patients, smokers and nonsmokers. Serum levels of IL-18 in COPD patients $(n=62)$ and smokers $(n=34)$ were significantly $(p<0.05)$ higher than in nonsmokers $(n=47$; table 4$)$. Next, the 62 COPD patients were categorised according to the GOLD classification of severity of COPD [22]. Serum IL-18 levels in GOLD stage I $(n=14)$, II $(\mathrm{n}=19)$, III $(\mathrm{n}=16)$ and IV $(\mathrm{n}=13)$ COPD patients were $178.2 \pm 18.3,185.7 \pm 9.8,267.0 \pm 23.4$, and $293.9 \pm 19.3 \mathrm{pg} \cdot \mathrm{mL}^{-1}$, respectively. Serum levels of IL-18 in GOLD stages III and IV were significantly $(\mathrm{p}<0.05)$ higher than those in smokers and nonsmokers (fig. 6). There were no significant differences in serum IL-18 levels between current and ex-smokers within the COPD group. Smoking history in patients with COPD stages I, II, III and IV were 53.4 $\pm 8.3,60.0 \pm 7.1,53.3 \pm 5.8$ and $50.0 \pm 4.0$ pack-yrs, respectively. There were no significant correlations between smoking history (pack-yrs) and serum levels of IL-18 in smokers and COPD patients. There were no significant differences in serum IL-18 levels between males and females in the nonsmoker, smoker or COPD groups (data not shown). Serum levels of IL-13, -4 , and IFN- $\gamma$ were not significantly increased in smokers or in COPD patients (table 4).

\section{Negative correlation between serum levels of IL-18 and FEV $1 \%$ pred}

The correlation between serum levels of IL-18 and pulmonary function was analysed in nonsmokers, smokers and COPD patients. In COPD patients, there was a significant $(\mathrm{p}<0.001)$ negative correlation between serum level of IL-18 and FEV1 \% pred but not between serum IL-18 and FEV1/FVC \% $(\mathrm{r}=0.4844$; fig. 7$)$. In contrast, no significant correlations between serum levels of IL-18 and FEV1 \% pred were observed in nonsmokers or smokers.

\section{DISCUSSION}

In the present study, it was shown that IL-18 was strongly expressed in AMs and CD8+ T-cells in the lungs of patients with very severe COPD. The enhanced IL- 18 protein production in the AMs and CD8+ T-cells of COPD patients was presumably of both the pro- and mature IL-18 forms, as the anti-human-IL-18 monoclonal antibody (clone 8) used in the study recognises both forms [15]. However, when an ELISA specific for the mature form of IL-18 was used [15], serum levels of mature IL-18 protein in COPD and smokers were found to be significantly higher than in nonsmokers. A recent paper reported that cigarette smoke induced IL-18 production in the lungs of mice and that serum levels of IL-18 were increased in COPD patients [25]. The present authors found that: 1) IL-18 protein was strongly expressed in the majority of AMs and CD8+ T-cells, and in both the bronchiolar and alveolar epithelia of COPD patients; 2 ) the levels of mature IL18 protein were significantly greater in the sera of patients with GOLD stage III and IV COPD than in nonsmokers or smokers; and 3) a significant correlation existed between serum level of IL-18 and pulmonary function (FEV1 \% pred) in COPD patients, but not in non-smokers or smokers. These results suggest that cigarette smoke induces the production of large amounts of reactive oxygen species, activates the cascade of cathepsin-B-caspase-11-caspase-11, and induces mature IL-18 production [26] in AMs and IMNCs in the lungs of COPD patients, leading to higher levels of mature IL-18 in the sera of these patients. Previous studies have shown that mature IL-18 proteins are tightly bound to IL-18 binding protein [27] and/or IgM [28] in human sera. Mature IL-18 complexed with IL-18BP and/or IgM does not degrade readily, and this complex is easily detectable by ELISA. It has been reported that FEV1 \% pred is an important prognostic factor in COPD [29, 30]. The present study showed that a significant correlation existed between serum level of IL-18 and pulmonary function (FEV1 \% pred) in COPD patients. Therefore, mature IL-18 in the sera can be used as a new biomarker for disease activity in COPD. However, the mechanisms controlling cytokine production usually differ between lung tissue and peripheral blood. Analysis of IL-18 protein expression in lung and blood samples from the same COPD patients may be necessary to verify this issue. However, the present authors were unable to obtain paired tissue and blood samples from COPD patients. Further analysis is needed to confirm this model. 

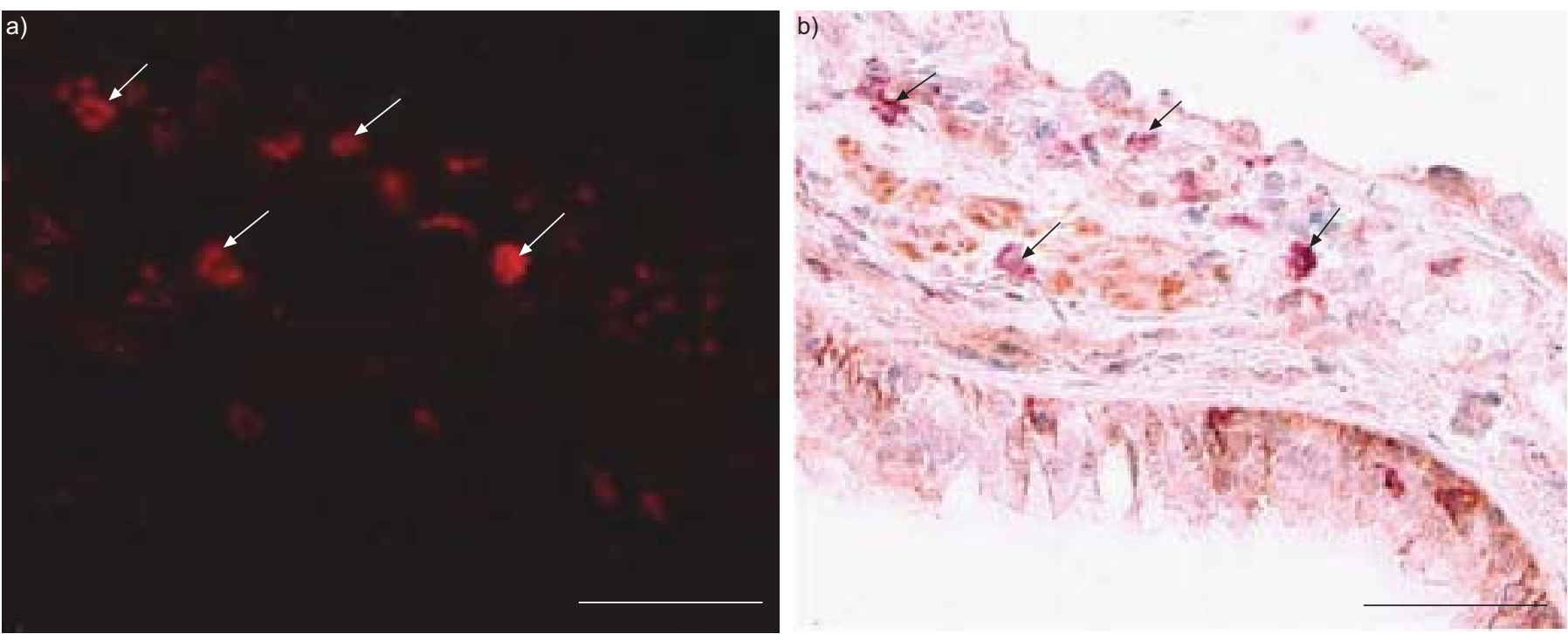

FIGURE 4. Double immunostaining of lung tissue samples with a) mouse anti-CD8 alone and b) in combination with mouse anti-interleukin (IL)-18 monoclonal antibodies on one slide in chronic obstructive pulmonary disease patient 2. CD8 positive cells were identified with Fast Red staining under a fluorescent microscope (arrows) IL-18 positive reactivity was identified by 3-3'-diaminobenzidine- $4 \mathrm{HCl}$ treatment (b). Scale bars $=50 \mu \mathrm{m}$.

Previous studies have shown that there is persistent inflammation in the small airways of both ex-smokers and smokers. For instance, airway obstruction and chronic expectoration are associated with increased numbers of neutrophils in the sputum of smokers and ex-smokers [31]. Induced sputum samples obtained from COPD patients who have stopped smoking and from current smokers with COPD show increased neutrophil numbers [32]. The presence of persistent and severe small airway inflammation has been confirmed in the resected lung tissues of ex-smokers with very severe COPD. The present results show that cessation of smoking cannot prevent pulmonary inflammation in severe COPD.

It has been reported that oestrogen levels can modulate the production of some cytokines from peripheral blood mononuclear cells [33], suggesting that sex differences may influence the production of IL-18. Therefore, the effect of sex on numbers

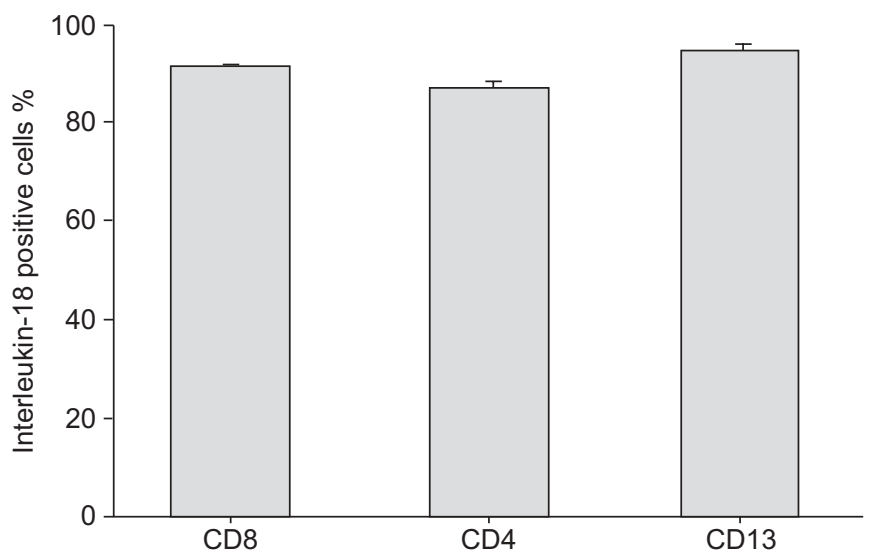

FIGURE 5. Interleukin-18 positive cells in CD8+, CD4+ and CD13+ cells in the lungs of 16 chronic obstructive pulmonary disease patients. Whiskers represent SEM. of AMs and IMNCs and on IL-18 expression levels was analysed in the lung tissues obtained from nonsmokers and smokers. In nonsmokers or smokers there were no significant differences between males and females in terms of the numbers of AMs and IMNCs or IL-18 expression levels. Moreover, levels of IL-18 in the sera were not significantly different between males and females in the nonsmoking, smoking or COPD groups (data not shown). Although lung tissues from female patients with very severe COPD could not be obtained, the present results suggest that sex differences may not influence IL-18 production.

The numbers of AMs and IMNCs were significantly greater in smokers than in nonsmokers. These results suggest that acute smoking may induce pulmonary inflammation in both smokers with COPD and smokers with normal lung function. The present authors wanted to compare the levels of IL-18 protein expression in the lungs of current smokers with normal lung function and of current smokers with very severe COPD (GOLD stage IV). However, lung tissues from patients with

TABLE 4 Serum levels of interleukin (IL)-18, -13, -4 and interferon (IFN) $-\gamma$ in chronic obstructive pulmonary disease (COPD) patients, smokers and nonsmokers

\begin{tabular}{lccc} 
& Nonsmoker & Smoker & COPD \\
\hline Subjects $\mathbf{n}$ & 47 & 34 & 62 \\
Serum IL-18 $\mathbf{~ g ~} \cdot \mathbf{m L}^{-1}$ & $126.0 \pm 10.2$ & $205.5 \pm 13.6^{\star}$ & $227.6 \pm 10.7^{\star}$ \\
Serum IL-13 $\mathbf{~ g} \cdot \mathbf{m L}^{-1}$ & $23.1 \pm 9.4$ & $21.4 \pm 7.9$ & $24.4 \pm 10.0$ \\
Serum IL-4 $\mathbf{~ g} \cdot \mathbf{m L}^{-1}$ & $3.0 \pm 0.7$ & $3.9 \pm 1.1$ & $3.0 \pm 0.6$ \\
Serum IFN- $\gamma \mathbf{p g} \cdot \mathbf{m L}^{-1}$ & $1.9 \pm 0.7$ & $2.0 \pm 0.7$ & $2.2 \pm 0.6$ \\
\hline
\end{tabular}

Data are presented as mean \pm SEM, unless otherwise stated. *: $p<0.05$ versus nonsmokers. 


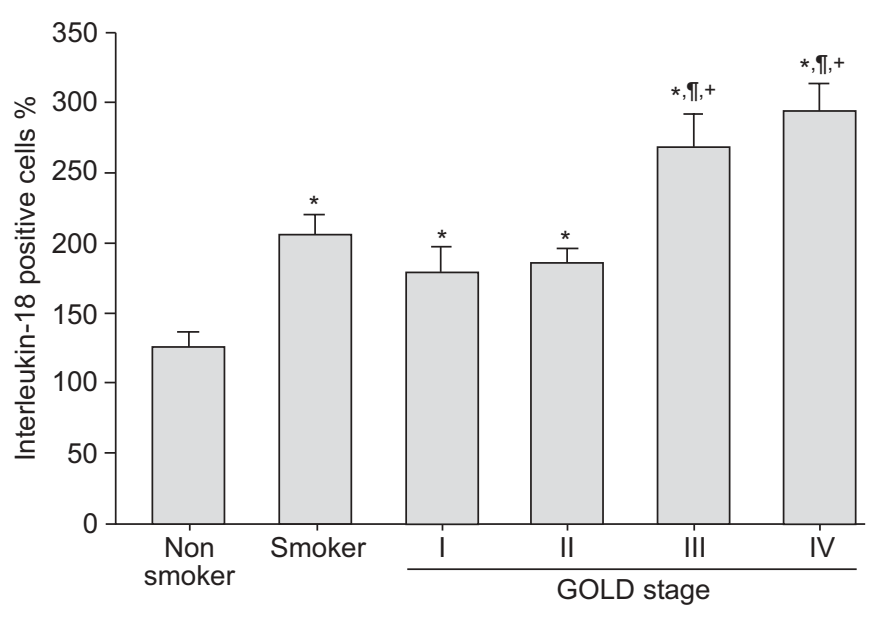

FIGURE 6. Serum levels of interleukin- 18 in nonsmokers $(n=47)$, smokers $(n=34)$ and chronic obstructive pulmonary disease (COPD) patients classified according to Global Initiative for Chronic Obstructive Lung Disease (GOLD) stages I $(n=14), \|(n=19), I I I(n=16)$ and IV $(n=13) .{ }^{*}: p<0.05$ versus nonsmokers; ": $p<0.05$ versus smokers; ${ }^{+}: p<0.05$ versus patients with GOLD stage I COPD and $p<0.05$ versus patients with GOLD stage II COPD.

very severe COPD who were current smokers could not be obtained. Further analysis is needed to verify this issue.

Six patients with very severe COPD (GOLD stage IV) were receiving inhaled corticosteroids (ICS) at the time of LVRS. A total of 15 patients with COPD (GOLD stage III and IV) were using ICS when their sera were obtained for ELISA analysis. None of the COPD patients analysed had been receiving systemic steroid therapy. It is of note that there were no significant differences between COPD patients treated or not treated with ICS in terms of IL-18 expression levels in the lungs and sera (data not shown). These results suggest that IL-18 production may not be influenced by ICS treatment. However, a previous study [34] reported that steroids suppressed the production of IL-18 in lipopolysaccharide-/IL-2-stimulated peripheral blood mononuclear cells in vitro. Further analysis is needed to verify whether steroids can influence IL-18 production in COPD patients.

As described previously, IL-13 and IFN- $\gamma$ are thought to play important roles in the pathogenesis of COPD [7, 12, 13]. It has been previously demonstrated that IL-18 induces the production of both Th1- and Th2-type cytokines, including IL-13, -4 and IFN- $\gamma$, both in vitro and in vivo [16-18]. Very recently, the present authors established lung-specific IL-18 Tg mice that constitutively overproduce IL-18 in their lungs. Constitutive overproduction of IL-18 in the lungs results in: increased production of both Th1 and Th2 cytokines, including IFN- $\gamma$ and IL-13; emphysematous changes; and severe pulmonary inflammation in mice [20]. Increased numbers of CD8+ T-cells are characteristic pathological features of the lungs in COPD [3, 4]. In the present study, it was shown that the numbers of CD8+ T-cells were increased in the lungs of patients with very severe COPD, and $\sim 90 \%$ of these CD $8+$ T-cells produced IL-18 proteins. The majority of CD8+ T-cells and alveolar macrophages in the lungs of COPD produced IL-18. Enhanced IL-18 production may induce the subsequent localised production of Th1- or Th2-associated cytokines in the lungs of COPD

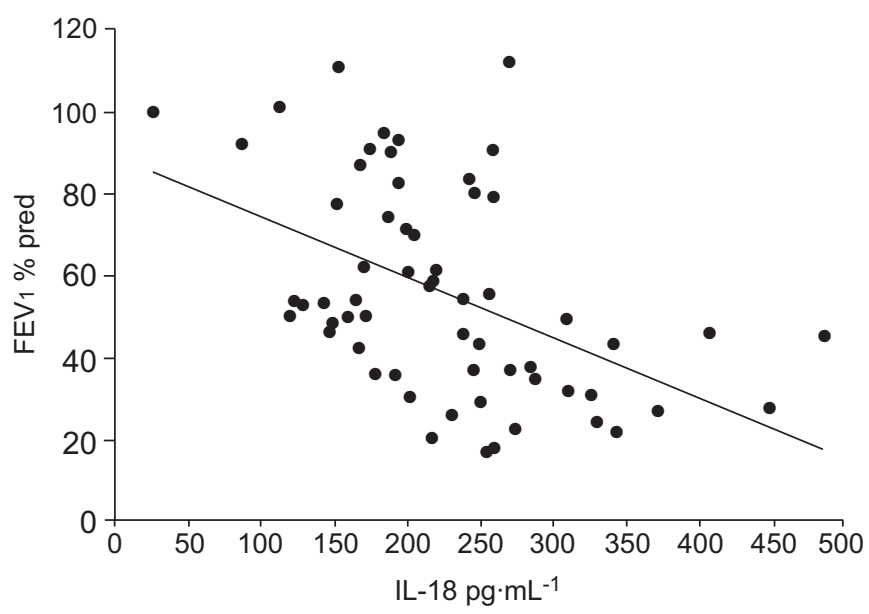

FIGURE 7. Correlation between serum levels of mature interleukin (IL)-18 and lung function measured as forced expiratory volume in one second (FEV1) \% predicted in chronic obstructive pulmonary disease patients $(n=62)$. The gradient and intercept of the best-fit line are -0.14721 and 88.9083 , respectively $(r=0.4844$ and $\mathrm{p}<0.001$ )

patients. IL-18-producing CD8+ T-cells and alveolar macrophages may be involved in the pathogenesis of COPD. Further analysis is needed to confirm this hypothesis.

The treatment strategy for chronic obstructive pulmonary disease consists mainly of the use of bronchodilators, such as $\beta_{2}$-agonists, theophylline and anticholinergics [22]. There is no effective therapy to reduce the persistent pulmonary inflammation in chronic obstructive pulmonary disease patients and improve their prognosis, even in those patients who use inhaled corticosteroids $[35,36]$. Therefore, the disease is being targeted with new anti-inflammatory treatments. In the present study, the overproduction of interleukin-18 in the lungs of chronic obstructive pulmonary disease patients has been demonstrated. The present results raise the possibility that blockade of interleukin-18 may be a feasible treatment for chronic obstructive pulmonary disease. Caspase- 1 inhibitors, antibodies to interleukin-18 and their receptor, interleukin-18 binding protien, or inhibitors of genes downstream of the interleukin-18 signal transduction pathway, such as those encoding MyD88, interleukin-1 receptor associated kinase, tumour necrosis factor receptor-associated factor 6, nuclear factor- $\kappa \mathrm{B}, \mathrm{C}$-jun $\mathrm{N}$-terminal kinase, and p38 mitogen-activated protein kinase, as well as interleukin-13 inhibitors, may be of clinical benefit in the treatment of severe chronic obstructive pulmonary disease patients who have poor clinical prognoses.

\section{ACKNOWLEDGEMENTS}

The authors would like to thank T. Iwanaga for contributing to the study. The authors also thank: H. A. Young (NCIFrederick) for editing; K. Ohshima for helpful discussions; and T. Koga, Y. Kitasato, Y. Sakazaki, K. Azuma, R. Toda, N. Edakuni (Kurume University), T. Shirakusa (Fukuoka University), Y. Doi (Chikugogawa Onsen Hospital), T. Tsuda (Kirigaoka Tsuda Hospital), T. Shigemoto (Shigemoto Hospital), M. Kawahara, H. Koga (Keisinkai Hospital), N. Tokunaga (Tokunaga-Naika Clinic), N. Hachiya (Social 
Insurance Futase Hospital) and T. Kukita (Arao Central Hospital) for supplying the COPD tissue samples. The authors would also thank E. Kuma, C. Harada, E. Hidaka and K. Yamaguchi for their technical assistance.

\section{REFERENCES}

1 Peto R, Chen ZM, Boreham J. Tobacco-the growing epidemic. Nat Med 1999; 5: 15-17.

2 Pauwels RA, Rabe KF. Burden and clinical features of chronic obstructive pulmonary disease (COPD). Lancet 2004; 364: 613-620.

3 Saetta M, Di Stefano A, Maestrelli P, et al. Activated Tlymphocytes and macrophages in bronchial mucosa of subjects with chronic bronchitis. Am Rev Respir Dis 1993; 147: 301-306.

4 Saetta M, Baraldo S, Corbino L, et al. CD8+ve cells in the lungs of smokers with chronic obstructive pulmonary disease. Am J Respir Crit Care Med 1999; 160: 711-717.

5 Saetta M, Di Stefano A, Maestrelli P, et al. Airway eosinophilia in chronic bronchitis during exacerbations. Am J Respir Crit Care Med 1994; 150: 1646-1652.

6 Barnes PJ, Hansel TT. Prospects for new drugs for chronic obstructive pulmonary disease. Lancet 2004; 364: 985-996.

7 Elias J. The relationship between asthma and COPD. Lessons from transgenic mice. Chest 2004; 126: Suppl. 2, 111S-116S; discussion 159S-161S.

8 Saetta M, Di Stefano A, Turato G, et al. CD8+ Tlymphocytes in peripheral airways of smokers with chronic obstructive pulmonary disease. Am J Respir Crit Care Med 1998; 157: 822-826.

9 Hardaker EL, Bacon AM, Carlson K, et al. Regulation of TNF- $\alpha$ - and IFN- $\gamma$-induced CXCL10 expression: participation of the airway smooth muscle in the pulmonary inflammatory response in chronic obstructive pulmonary disease. FASEB J 2004; 18: 191-193.

10 Miotto D, Ruggieri MP, Boschetto P, et al. Interleukin-13 and -4 expression in the central airways of smokers with chronic bronchitis. Eur Respir J 2003; 22: 602-608.

11 Boutten A, Bonay M, Laribe S, et al. Decreased expression of interleukin 13 in human lung emphysema. Thorax 2004; 59: 850-854.

12 Wang $Z$, Zheng $\mathrm{T}$, Zhu $\mathrm{Z}$, et al. Interferon $\gamma$ induction of pulmonary emphysema in the adult murine lung. $J$ Exp Med 2000; 192: 1587-1600.

13 Zheng T, Zhu Z, Wang Z, et al. Inducible targeting of IL-13 to the adult lung causes matrix metalloproteinase- and cathepsin-dependent emphysema. J Clin Invest 2000; 106: 1081-1093.

14 Nakanishi K, Yoshimoto $T$, Tsutsui $H$, Okamura $H$. Interleukin-18 regulates both Th1 and Th2 responses. Annu Rev Immunol 2001; 19: 423-474.

15 Kitasato Y, Hoshino T, Okamoto M, et al. Enhanced expression of interleukin-18 and its receptor in idiopathic pulmonary fibrosis. Am J Respir Cell Mol Biol 2004; 31: 619-625.

16 Hoshino T, Wiltrout RH, Young HA. IL-18 is a potent coinducer of IL-13 in NK and T cells: a new potential role for IL-18 in modulating the immune response. J Immunol 1999; 162: 5070-5077.

17 Hoshino T, Yagita H, Ortaldo JR, Wiltrout RH, Young HA. In vivo administration of IL-18 can induce IgE production through Th2 cytokine induction and up-regulation of CD40 ligand (CD154) expression on CD4+ T cells. Eur J Immunol 2000; 30: 1998-2006.

18 Hoshino T, Kawase Y, Okamoto M, et al. Cutting edge: IL18-transgenic mice: in vivo evidence of a broad role for IL18 in modulating immune function. J Immunol 2001; 166: 7014-7018.

19 Okamoto M, Kato S, Oizumi K, et al. Interleukin 18 (IL-18) in synergy with IL-2 induces lethal lung injury in mice: a potential role for cytokines, chemokines, and natural killer cells in the pathogenesis of interstitial pneumonia. Blood 2002; 99: 1289-198.

20 Hoshino T, Kato S, Oka N, et al. Pulmonary inflammation and emphysema: role of the cytokines IL-18 and IL-13. Am J Respir Crit Care Med 2007; 176: 49-62.

21 Kitasato Y, Hoshino T, Kato S, et al. Enhanced expresssion of IL-18 and its receptor in patients with chronic obstructive pulmonary disease. Am J Respir Crit Care Med 2006; 3: A629.

22 Global Initiative for Chronic Obstructive Lung Disease (GOLD). Global Strategy for the Diagnosis, Management, and Prevention of Chronic Obstructive Pulmonary Disease NHLBI/WHO Workshop report. Revised edition. 2006 www.goldcopd.com Date last accessed: November 25, 2006.

23 The Japanese Respiratory Society Statement of the Japanese Pulmonary Function Standard. Revised edition 2001 www.jrs.or.jp/quicklink/glsm/index.html Date last accessed: November 25, 2006.

24 Hogg JC, Chu F, Utokaparch S, et al. The nature of smallairway obstruction in chronic obstructive pulmonary disease. N Engl J Med 2004; 350: 2645-2653.

25 Kang MJ, Homer RJ, Gallo A, et al. IL-18 is induced and IL18 receptor $\alpha$ plays a critical cole in the pathogenesis of cigarette smoke-induced pulmonary emphysema and inflammation. J Immunol 2007; 178: 1948-1959.

26 Sekiyama A, Ueda H, Kashiwamura S, et al. A stressinduced, superoxide-mediated caspase-1 activation pathway causes plasma IL-18 upregulation. Immunity 2005; 22: 669-677.

27 Novick D, Kim SH, Fantuzzi G, Reznikov LL, Dinarello CA, Rubinstein M. Interleukin-18 binding protein: a novel modulator of the Th1 cytokine response. Immunity 1999; 10: 127-136.

28 Shida K, Shiratori I, Matsumoto M, et al. An alternative form of IL-18 in human blood plasma: complex formation with IgM defined by monoclonal antibodies. I Immunol 2001; 166: 6671-6679.

29 Traver GA, Cline MG, Burrows B. Predictors of mortality in chronic obstructive pulmonary disease. A 15-year follow-up study. Am Rev Respir Dis 1979; 119: 895-902.

30 Anthonisen NR, Wright EC, Hodgkin JE. Prognosis in chronic obstructive pulmonary disease. Am Rev Respir Dis 1986; 133: 14-20.

31 Stănescu D, Sanna A, Veriter C, et al. Airways obstruction, chronic expectoration, and rapid decline of FEV1 in smokers are associated with increased levels of sputum neutrophils. Thorax 1996; 51: 267-271.

32 Domagała-KulawikJ, Maskey-Warzechowska M, Kraszewska I, Chazan R. The cellular composition and macrophage 
phenotype in induced sputum in smokers and ex-smokers with COPD. Chest 2003; 123: 1054-1059.

33 Asai K, Hiki N, Mimura Y, Ogawa T, Unou K, Kaminishi M. Gender differences in cytokine secretion by human peripheral blood mononuclear cells: role of estrogen in modulating LPS-induced cytokine secretion in an $e x$ vivo septic model. Shock 2001; 16: 340-343.

34 Kodama M, Takahashi HK, Iwagaki $\mathrm{H}$, et al. Effect of steroids on lipopolysaccharide/interleukin 2-induced interleukin 18 production in peripheral blood mononuclear cells. J Int Med Res 2002; 30: 144-160.
35 Pauwels RA, Löfdahl CG, Laitinen LA, et al. Long-term treatment with inhaled budesonide in persons with mild chronic obstructive pulmonary disease who continue smoking. European Respiratory Society Study on Chronic Obstructive Pulmonary Disease. N Engl J Med 1999; 340: 1948-1953.

36 Burge PS, Calverley PM, Jones PW, Spencer S, Anderson JA, Maslen TK. Randomised, double blind, placebo controlled study of fluticasone propionate in patients with moderate to severe chronic obstructive pulmonary disease: the ISOLDE trial. BMJ 2000; 320: 1297-1303. 